Article

\title{
Effects of Drought-Flood Abrupt Alternation on the Growth of Summer Maize
}

\author{
Wuxia Bi ${ }^{1,2}{ }^{\mathbb{D}}$, Mengke Wang ${ }^{1,3}$, Baisha Weng ${ }^{1, * \mathbb{D}}$, Denghua Yan ${ }^{1}$, Yuheng Yang ${ }^{1}$ \\ and Jinjie Wang ${ }^{1}$ \\ 1 State Key Laboratory of Simulation and Regulation of Water Cycle in River Basin, China Institute of Water \\ Resources and Hydropower Research, Beijing 100038, China; 170201010001@hhu.edu.cn (W.B.); \\ mengkewang123@163.com (M.W.); yandh@iwhr.com (D.Y.); 1109080115@cau.edu.cn (Y.Y.); \\ ting774433@163.com (J.W.) \\ 2 College of Hydrology and Water Resources, Hohai University, Nanjing 210098, China \\ 3 College of Environmental Science and Engineering, State Environmental Protection Engineering Center for \\ Pollution Treatment and Control in Textile Industry, Donghua University, Shanghai 201620, China \\ * Correspondence: wengbs@iwhr.com
}

Received: 2 December 2019; Accepted: 23 December 2019; Published: 25 December 2019

check for updates

\begin{abstract}
Climate change, especially precipitation change, will significantly change soil moisture, which then influences root growth, further affecting yield and grain quality. Previous studies focused on the drought or flood effects on summer maize growth. However, few studied the effects of drought-flood abrupt alternation (DFAA) on the growth of summer maize. We explored the DFAA impacts on the roots, leaf area index (LAI), yield, and grain quality in field. The main results show that DFAA had different impacts on the summer maize growth in the seeding-jointing stage (SJS) and tasseling-grain filling stage (TGS). In general, the DFAA reduced the yield. Roots at the depth of $40 \mathrm{~cm}$ had obviously positive impacts on the yield. The DFAA reduced the LAI and promoted the maximum LAI achieving in advance. The grain crude protein augmented under DFAA. The drought had evidently negative impacts on the grain crude fat in the TGS, while it had no obvious influence in the SJS. DFAA had no apparent impact on the grain crude starch. These results could provide some references for the effects and adaptation-strategies study of extreme climate events and their impacts on growth of summer maize.
\end{abstract}

Keywords: drought-flood abrupt alternation; summer maize; root; grain yield; grain quality

\section{Introduction}

Global climate change has caused more prominent extreme hydrological events such as drought and flood [1-3]. A new type of extreme event named drought-flood abrupt alternation (DFAA) has increased significantly both in frequency and intensity [4,5]. First proposed in 2006, the term DFAA refers to persistent drought for certain continuous days in one basin or region, followed by sudden heavy precipitation, resulting in steep river water and farmland waterlogging [6]. Notably, DFAA is different from the dry-wet cycling and drying-rewetting as it demands specific drought and flood conditions.

Maize (Zea mays L.) is one of the main food crops in the world, and its high production could solve the food demand of many people $[7,8]$. However, the growth of maize is limited by several environmental factors, such as precipitation, temperature, light, pests, and so on [9-11]. In particular, extreme climate events such as drought and flood have severe impacts on the growth of maize due to the changes in the availability of water $[12,13]$. Roots play an important role in crop growth, as they can transfer water and nutrients for growth demand $[14,15]$. Therefore, it is sensitive to environmental changes and directly affects yield and grain quality. 
Previous studies revealed that maize roots grew deeply to absorb as much as water possible during drought [16]. Long-term drought decreased the yield in almost all the growing periods of maize, while drought occurring in the seeding stage augmented the yield as drought-resistance is strong during this period $[17,18]$. Short-duration water deficits during the rapid vegetative growth period caused $28 \%-32 \%$ loss of final dry matter weight. Much greater losses of $66 \%-93 \%$ could be expected as a result of prolonged water stress during tasseling and ear formation stages [17]. The leaf area index (LAI) increases first then decreases in the grain filling stage [19]. The drought could decrease the LAI to maintain the growth of other organs [20]. For grain quality evaluation, the contents of crude protein, crude starch, and crude fat are usually analyzed [21]. The drought effects on grain quality are not consistent according to other studies. The drought promoted crude protein formation [22]. The crude starch and crude fat had no significant correlation to water content, thus their contents were less influenced by the drought [21], yet some studies show that crude fat decreases when drought occurred in the grain filling stage [23]. The flood could also accelerate the roots' death, further reducing the yield [24]. The flood had negative impacts on crude protein content as water dilutes the nutrients [25]. Some studies focused on the dry-rewetting process. The growth conditions vary with drought duration. The rewetting may meet the water demand after a light drought but cannot relieve the water deficit after a long-term drought, which reduces the yield [26].

The existing studies were primarily concerned with single drought events, single flood events, drying-rewetting process or dry-wet cycling on crop growth, few focused on DFAA effects on crop growth. Therefore, it is of great significance to study the DFAA effects on crop growth, including roots, LAI, yield, and grain quality, especially conducted under field conditions.

Under these circumstances, this study focuses on the effects of DFAA with different drought durations on the growth of summer maize based on field experiments. The main index contains roots, LAI, yield, and grain quality (crude protein, crude starch, and crude fat). The main objectives were to: (i) investigate the summer maize growth condition under DFAA; (ii) explore the effects of environmental factors (i.e., soil moisture content and soil microbial communities), on summer maize growth (especially the roots) under DFAA; and (iii) reveal the mechanism of DFAA on the growth of summer maize. The impact analysis of DFAA on summer maize growth can provide references for disaster risk reduction, agricultural development, and relevant research. Additionally, the results of field experiments can guide the local adaptation strategies for extreme climate events.

\section{Materials and Methods}

\subsection{Site Description and Experimental Design}

The experiments were conducted at the Wudaogou Experimentation Research Station $\left(33^{\circ} 09^{\prime} \mathrm{N}\right.$, $\left.117^{\circ} 21^{\prime} \mathrm{E}\right)$, Bengbu, Anhui Province, China. It has a north subtropical and semi-humid warm temperate continental monsoon climate. From 1963 to 2017, the average temperature was $14.6^{\circ} \mathrm{C}$ and the average annual precipitation was $890 \mathrm{~mm}$ with $60 \%$ or more concentrated in the summer. Anhui Province is located in the Huaibei Plain, which is one of the most important agricultural regions in China.

The study area is prone to DFAA. Statistics show that, from 1949 to 2006, the study site had experienced typical DFAA events for 21 years [27], which mainly occurred in late July and early August. The soil in this area is dark-hydromorphic clay loam, with the characteristics of poor structure, heavy texture, and low organic matter content. These characteristics strengthen the DFAA impact on crops.

The DFAA levels are determined by the drought level and the flood level. Drought level is evaluated by the Classification of Meteorological Drought of China (GB/T 20481-2006) combined with the water demand of summer maize. Light drought refers to the soil relative moisture (in the soil layer of 10 to $20 \mathrm{~cm}$ ) of $60 \%$ to $50 \%$. Moderate drought refers to the soil relative moisture of $50 \%$ to $40 \%$. As the soil field capacity in the soil layer of 10 to $20 \mathrm{~cm}$ is about $30 \%$ in the study site, the soil water content corresponding to the light drought is set in the range of $18 \%$ to $15 \%$, and $15 \%$ to $12 \%$ for the moderate drought. When soil water content reaches the upper limits of the drought level, we 
measured soil water content every $12 \mathrm{~h}$. When there were three to five values (i.e., 2 to 3 days) in the range of drought level, we conducted the artificial rainfall experiments.

The short-term precipitation after drought is evaluated for the flood level. Specific calculation methods can be found in [28]. The flood levels were determined by the total precipitation amount within 5 days after the drought. In one precipitation process, when the precipitation amount far exceeded the infiltration amount, it was considered that a flood would occur. The infiltration amount is the product of the precipitation amount and the infiltration coefficient. The main characteristic of the DFAA is the sudden change from drought to flood. Therefore, the DFAA mainly concerns the flood caused by short-term and intensive precipitation process. When classifying the floods level, the annual maximum $n$-day precipitation is applied to calculate the threshold of infiltration in the DFAA (Equation (1)).

$$
I_{n}=\alpha P_{n}
$$

where, $I_{n}$ is the infiltration amount of continuous precipitation for $n$ days in $\mathrm{mm} ; n$ is the number of continuous rainy days; $\alpha$ is the infiltration coefficient, mainly affected by precipitation, groundwater depth, underlying surface conditions, and evaporation. In previous studies the infiltration coefficient is about 0.23 in the Huaibei Plain (i.e., $\alpha$ equals to 0.22 in this study [29]. $P_{n}$ is the multi-year average of the annual maximum $n$-day precipitation in $\mathrm{mm}$.

The floods levels are based on the precipitation threshold, which is in accordance with the infiltration threshold. Equations (2) and (3) calculate the precipitation threshold.

$$
\begin{gathered}
P T_{j n}=k I_{n} \\
k=k_{0}+j+\beta(n-1)
\end{gathered}
$$

where, $P T_{j n}$ is the precipitation threshold in $\mathrm{mm}$. $j$ is the flood level, when $j$ is equal to 0,1 , and 2 , and the corresponding flood level is light flood, moderate flood, and severe flood. $k_{0}$ is an undetermined coefficient. Referring to the historical flood data in the Huaibei Plain, when $k_{0}=3.5$, it is considered that the daily precipitation in the basin reaches the light flood level. $k$ is the corrected value of $k_{0}$, related to the flood level and cumulative rainy days. $\beta$ is an undetermined coefficient, when $j$ is equal to 0,1 , and $2, \beta$ is equal to $0.5,0.7$, and 1 , respectively.

According to the historical meteorological data in the Huaibei Plain, most DFAA events were light drought-light flood and several were moderate drought-light flood. Thus, these two types of DFAA treatments were designed to investigate the effects of DFAA on summer maize in this study. The short-term precipitation corresponding to the light flood was $100 \mathrm{~mm}$ in the study area.

The growing period of maize comprises five stages: the seeding stage, jointing stage, tasseling stage, grain filling stage, and mature stage. We explored the DFAA effects by dividing the summer maize growing periods into two stages: seeding-jointing stage (i.e., seeding stage and jointing stage, SJS) and tasseling-grain filling stage (i.e., tasseling stage and grain filling stage, TGS).

The DFAA assay was performed with four treatments to distinguish between different DFAA levels in different growing periods; they were DFAA1 (light drought-light flood in the SJS), DFAA2 (moderate drought-light flood in the SJS), DFAA3 (light drought-light flood in the TGS), and DFAA4 (moderate drought-light flood in the TGS). In particular, a control system (CK) was operated under the natural climate conditions.

Each treatment had 3 replicates, thus 15 experimental plots (length $\times$ width $=3.7 \mathrm{~m} \times 5.5 \mathrm{~m}$ ) were formed for the experiment. Aluminum plastic composite panels with a depth of $1.2 \mathrm{~m}$ were used as baffles surrounding each experimental plot to prevent external water and groundwater from the other experimental plots. The four DFAA treatments were conducted at local farmland and were sheltered under a ventilation shed with an artificial rainfall device to prevent external precipitation and simulate consecutive rainless conditions and abrupt precipitation conditions. All the tests were conducted in the growing season of summer maize (Deng-Hai 618) from 25 June to 9 October 2018. The plant density

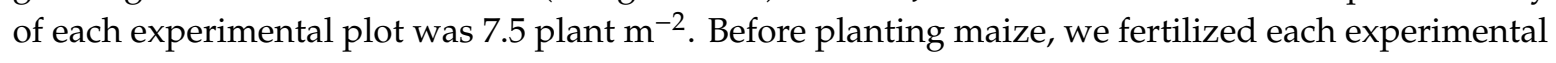


plot with $75 \mathrm{~g} \mathrm{~m}^{-2}$ of compound fertilizer of potassium sulfate and $30 \mathrm{~g} \mathrm{~m}^{-2}$ of urea. During the experiment, no more fertilizer was added. The initial conditions (soil moisture, $\mathrm{P}$ addition, and so on) were kept the same for all the experimental plots. The design details for different experimental treatments can be found in Figure 1 and Table 1.
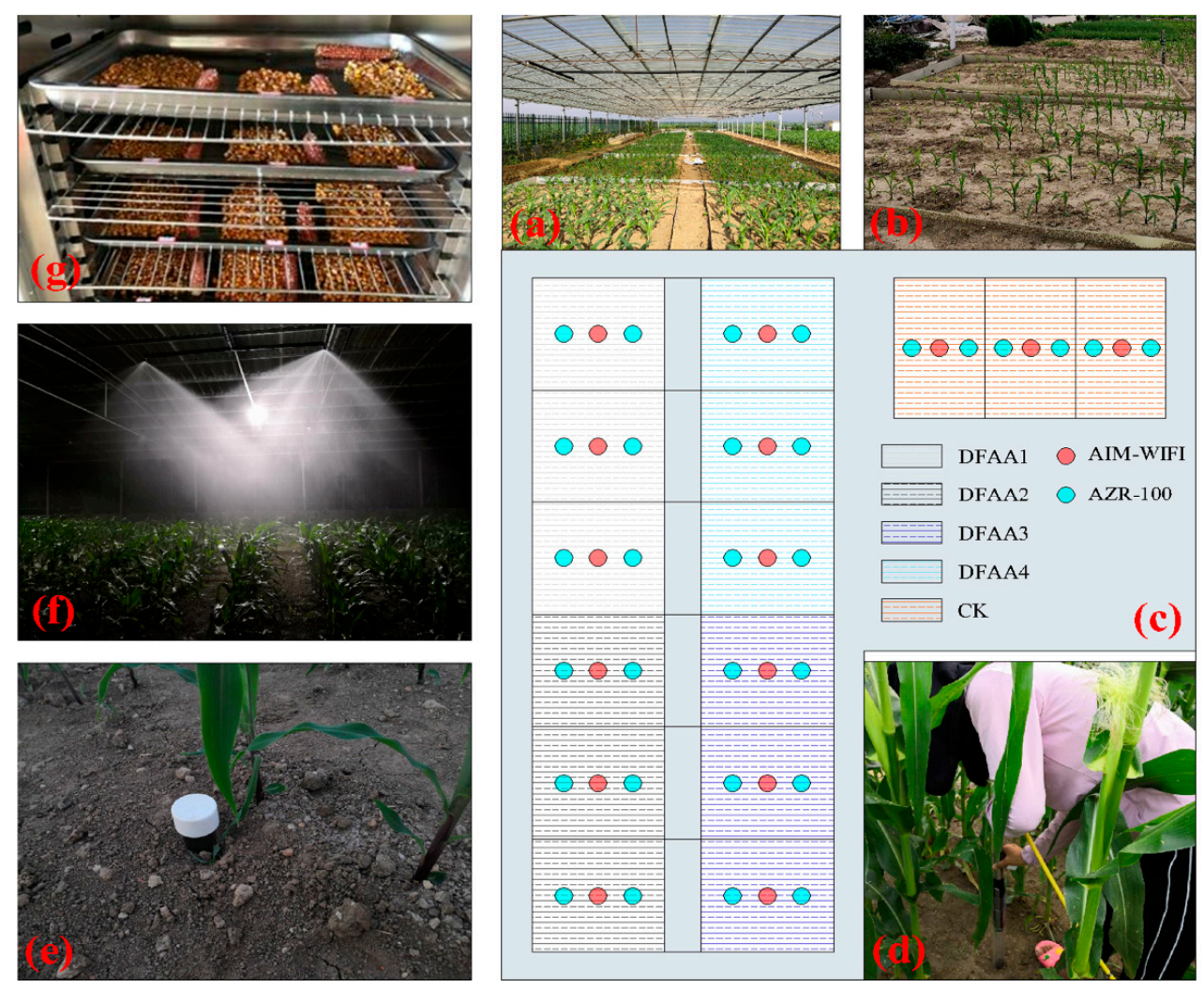

Figure 1. The experimental plots and corresponding devices. (a) The experimental plots for the drought-flood abrupt alternation (DFAA) treatments; (b) the experimental plots for the control system (CK) treatment; (c) the experimental plots design; (d) soil moisture measurement by the AIM-WiFi soil multi-parameters monitoring system (red points in (c)); (e) root observation by the AZR-100 root ecological detection system (blue points in (c)); (f) the artificial rainfall device; (g) oven-drying for grain quality measurement. DFAA1 represents the light drought-light flood treatment in the seeding-jointing stage; DFAA2 represents the moderate drought-light flood treatment in the seeding-jointing stage; DFAA3 represents the light drought-light flood treatment in the tasseling-grain filling stage; DFAA4 represents the moderate drought-light flood treatment in the tasseling-grain filling stage; CK represents the control system.

Table 1. Drought and flood sets in different experimental treatments.

\begin{tabular}{ccccccc}
\hline \multirow{2}{*}{ Treatment } & \multicolumn{3}{c}{ Drought Set } & \multicolumn{3}{c}{ Flood Set } \\
\cline { 2 - 7 } & $\begin{array}{c}\text { Soil Moisture } \\
\mathbf{( \% )}\end{array}$ & $\begin{array}{c}\text { Drought } \\
\text { Duration (Days) }\end{array}$ & $\begin{array}{c}\text { Drought } \\
\text { Level }\end{array}$ & $\begin{array}{c}\text { Rainfall } \\
\mathbf{( m m )}\end{array}$ & Rainfall Date & $\begin{array}{c}\text { Flood } \\
\text { Level }\end{array}$ \\
\hline DFAA1 & 18 & 25 & light & 100 & 21 July & light \\
DFAA2 & 15 & 31 & moderate & 100 & 27 July & light \\
DFAA3 & 18 & 26 & light & 100 & 6 September & light \\
DFAA4 & 15 & 31 & moderate & 100 & 11 September & light \\
CK & - & - & - & 84.5 & 13 August & - \\
\hline
\end{tabular}

Note: DFAA1 represents the light drought-light flood treatment in the seeding-jointing stage; DFAA2 represents the moderate drought-light flood treatment in the seeding-jointing stage; DFAA3 represents the light drought-light flood treatment in the tasseling-grain filling stage; DFAA4 represents the moderate drought-light flood treatment in the tasseling-grain filling stage; CK represents the control system. 


\subsection{Soil Moisture Measurement}

Soil water content was measured from 6:30 a.m. to 7:30 a.m. (GMT +8) each day with an AIM-WiFi soil multi-parameters monitoring system (Beijing Aozuo Ecology Instrumentation Ltd., Beijing, China) using the time domain reflectometry principle. The rated accuracy was 1\% (Figure 1d). Data were conducted in triplicate in each experimental plot.

\subsection{Roots Measurement and Analysis}

The roots were observed by an AZR-100 root ecosystem detection system by Beijing Aozuo Ecology Instrumentation Ltd. (Beijing, China). This instrument has the advantage of achieving root analysis without destroying the crop. The routable micro camera was applied to photograph the roots in a certain soil layer depth. One photo was taken every $45^{\circ}$ of rotation, thus in total, eight photos were obtained in each soil layer. The photos were analyzed by the associated software WinRHIZOTron (Regent Instruments Inc., Quebec, Canada) to obtain relevant parameters of root, such as, total length, total projected area, total surface area, average diameter, total volume, and total number of tips. The root data in four soil layers were collected at the end of the mature stage on 9 October 2018, with layer depths of $20 \mathrm{~cm}, 40 \mathrm{~cm}, 60 \mathrm{~cm}$, and $80 \mathrm{~cm}$. The amount of total roots in a certain soil layer was the sum of the roots in the eight photos.

\subsection{Soil Microorganism Sampling and Analysis}

For analysis, $5 \mathrm{~g}$ each soil samples were collected from $0-20 \mathrm{~cm}$ and $20-40 \mathrm{~cm}$ depths from each experimental plot. The soil microorganism samples were collected 3 days after every artificial rainfall or natural rainfall (CK). Soils samples were transported on dry ice to the Shanghai Majorbio Bio-Pharm Technology Co. Ltd., China, which provides the polymerase chain reaction (PCR) amplification and analysis process technology. Each microbial sample was added into a $100 \mathrm{~mL}$ sterile centrifuge tube, mixed with $25 \mathrm{~mL}$ TENP buffer ( $50 \mathrm{mM}$ Tris- $\mathrm{HCl}, 20 \mathrm{mM}$ EDTA (ethylenediaminetetraacetic acid), $100 \mathrm{mM} \mathrm{NaCl}, 0.01 \mathrm{~g} \mathrm{~mL}^{-1}$ PVPP (polyvinyl-polypyrrolidone), $\mathrm{pH} 10.0$ ), then shaken for $5 \mathrm{~min}$, and centrifuged at 10,000 rpm for $5 \mathrm{~min}$ at room temperature. The supernatant was removed, and the pellets were extracted for a second round using the above method. Then, the pellets were mixed with $25 \mathrm{~mL}$ PBS buffer $\left(8.00 \mathrm{mg} \mathrm{L}^{-1} \mathrm{NaCl}, 0.20 \mathrm{mg} \mathrm{L}^{-1} \mathrm{KCl}, 1.44 \mathrm{mg} \mathrm{L}^{-1} \mathrm{Na}_{2} \mathrm{HPO}_{4}, 0.24 \mathrm{mg} \mathrm{L}^{-1} \mathrm{KH}_{2} \mathrm{PO}_{4}\right.$, $\mathrm{pH}$ 7.4), shaken for $5 \mathrm{~min}$, and centrifuged at $10,000 \mathrm{rpm}$ for $5 \mathrm{~min}$ at room temperature. Finally, the pellet of each sample was extracted with OMEGA Soil DNA Kit (Omega Bio-Tek Inc., Norcross, GA, USA) in accordance with the manufacturer's instructions. The universal bacterial primers of $338 \mathrm{~F}$ (5'-ACTCCTACGGGAGGCAGCAG-3') and 806R (5'-ACTCCTACGGGAGGCAGCAG-3') were used for polymerase chain reaction (PCR) amplification of bacterial communities. The PCR amplification process involved: (i) initial denaturation for $3 \mathrm{~min}$ at $95^{\circ} \mathrm{C}$; (ii) 27 cycles for $30 \mathrm{~s}$ at $95^{\circ} \mathrm{C}, 30 \mathrm{~s}$ at $55^{\circ} \mathrm{C}$, $45 \mathrm{~s}$ at $72{ }^{\circ} \mathrm{C}$; and (iii) final extension for $10 \mathrm{~min}$ at $72{ }^{\circ} \mathrm{C}$.

\subsection{Leaf Area Index Measurement and Analysis}

The LAI of summer maize was measured with a Yaxin-1242 portable leaf area meter by Beijing Yaxin Liyi Technology Co. Ltd. (Beijing, China), which is widely used with high accuracy, high speed, and easy operation. Several parameters of non-detached leaf can be obtained, such as area, perimeter, length, width, ratio of length to width, and shape factor. Throughout the experiment, the LAI was measured every five days from later seeding stage to the mature stage. The LAI can be calculated as follows (Equation (4)).

$$
L A I=\frac{N_{p} \times \frac{\sum_{i=1}^{n} A_{l, i}}{n}}{A_{\text {plot }}}
$$

where, $L A I$ is the leaf area index of each experimental plot; $N_{p}$ is the number of summer maize plants in each experimental plot; $A_{l, i}$ is the total area of all leaves of the $i$ th $(i=1,2, \ldots, n)$ measured plant; 
$n$ is the number of measured plants, $n$ is equal to 3 in this study; $A_{\text {plot }}$ is the surface area of the experimental plot.

\subsection{Yield Measurement and Analysis}

Six maize fruits were randomly sampled in each experimental plot at harvest. The number of ear rows and columns, ear length, total number of grains, and 100-seed weight were measured in lab. Notably, the yield was calculated with the dry grain weight and other parameters were measured with the fresh weight. The samples were naturally air-dried for yield. The yield can be calculated as follows (Equation (5)).

$$
G Y=\frac{E P N \times N G \times \frac{S W_{100}}{100}}{A_{\text {plot }}}
$$

where, GY is the yield of each experimental plot; $E P N$ is the effective plant number of summer maize in each experimental plot; $N G$ is the average total grains number in one plant; $S W_{100}$ is the average 100 -seed weight; $A_{\text {plot }}$ is the surface area of the experimental plot.

\subsection{Grain Quality Measurement and Analysis}

Six maize fruits were randomly sampled in each experimental plot at harvest. The crude protein, crude starch, and crude fat content in the grains were analyzed. These three parameters were measured according to the methods proposed by $\mathrm{Lu}$ [30]. The crude protein is determined based on the nitrogen concentration. The crude protein content was 6.25 times the nitrogen concentration for maize. The nitrogen concentration was measured by the elemental analyzer Shimadzu TOC-VCPH Organic Carbon Analyzer (Kyoto, Japan). The crude starch was measured by the $\mathrm{CaCl}_{2}-\mathrm{HOAc}$ extraction-polarimetry method. $\mathrm{CaCl}_{2}-\mathrm{HOAc}$ (relative density 1.3, $\mathrm{pH}$ 2.3) is used as a dispersing and liquefying agent. Under certain acidity and heating conditions, the starch is dissolved and partially acidified to form a hydrolysate with certain optical rotation, which can be measured by a polarimeter. The specific rotation of the hydrolysate of various starches is specified as 203 in this method. The crude fat was measured by the residual method. The fat was extracted with an organic solvent miscible in the YG-2 fat extractor. The crude fat content is the weight difference between the sample and the residue.

\subsection{Statistical and Data Analysis}

For the yield and grain quality, data were conducted in sextuplicate and the values were given in terms of their mean + standard deviation. One-way analysis of variance (ANOVA) was used to compare the difference among all the treatments. The significance of linear correlations between parameters was expressed as the Pearson's product moment correlation coefficient. A statistical difference was considered significant when $p<0.05$. All the data processing was performed using SPP version 20.0 (SPSS Inc., Chicago, IL, USA). The figures were drawn in Origin version 9.0 (OriginLab Inc., Hampton, MA, USA). The soil microorganism was analyzed with Circos (Vancouver, Cnanada) [31].

\section{Results}

\subsection{Soil Moisture Content}

The soil moisture content decreased slightly during the five consecutive days before the rainfall in all treatments (Figure 2). After the rainfall, the soil moisture content augmented rapidly in one day in both two topsoil layers. In the light DFAA treatments (DFAA1 and DFAA3), the soil moisture content had a smooth decrease after the one-day increase (Figure $2 \mathrm{a}, \mathrm{c}$ ). While in the moderate DFAA treatments (DFAA2 and DFAA4) and CK treatment, the soil moisture content increased after the one-day sharp increase (Figure $2 \mathrm{~b}, \mathrm{~d}, \mathrm{e}$ ). The increase rate was much larger in the moderate DFAA treatments compared to the CK treatment. In general, the soil moisture content in the TGS was higher than in the SJS during the DFAA period. Meanwhile, the soil moisture content during the DFAA 
period in the DFAA treatments varied more sharply than during the natural rainfall period in the CK treatment.
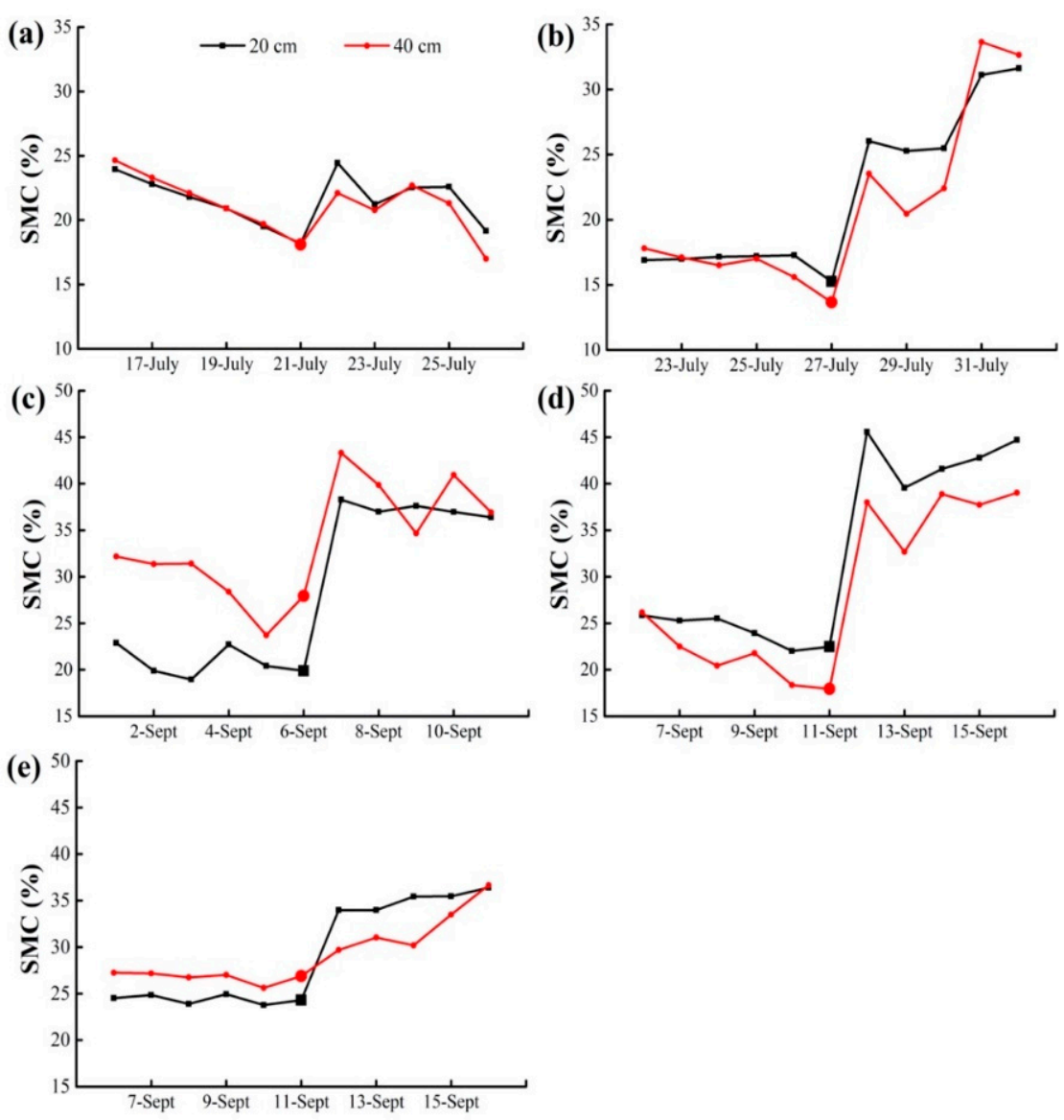

Figure 2. The soil moisture content during the DFAA period (five consecutive days before and after the rainfall). (a) DFAA1 treatment; (b) DFAA2 treatment; (c) DFAA3 treatment; (d) DFAA4 treatment; (e) CK treatment. The thicker points correspond to the rainfall date. SMC represents the soil moisture content, $20 \mathrm{~cm}$ represents the soil layer of $20 \mathrm{~cm}, 40 \mathrm{~cm}$ represents the soil layer of $40 \mathrm{~cm}$.

\subsection{Root Systems}

The total root surface area (TSA) and the total number of root tips (TNT) mainly concentrated in the soil depth of $20 \mathrm{~cm}$ and $40 \mathrm{~cm}$, with a total proportion of about $80 \%$. The TSA and TNT were larger in the soil depth of $60 \mathrm{~cm}$ than $80 \mathrm{~cm}$, with values of $5 \%$ to $10 \%$. In the SJS, in the light DFAA, the TSA and TNT were higher in the soil depth of $20 \mathrm{~cm}$ than $40 \mathrm{~cm}$ (Figure 3a), while the opposite trend was found in the moderate DFAA (Figure $3 b$ ). In the TGS, in the light DFAA, the TSA and TNT were higher in the soil depth of $40 \mathrm{~cm}$ compared to $20 \mathrm{~cm}$ (Figure 3c), while contrary result were shown in the moderate DFAA (Figure 3d). The TSA and TNT were much larger in the soil depth of $40 \mathrm{~m}$ than $20 \mathrm{~cm}$ in the CK treatment (Figure 3e) with a difference of $20 \%$.

\subsection{Soil Bacterial Communities}

The relatively abundant soil bacterial communities of summer maize were phyla Proteobacteria, Actinobacteria, and Acidobacteria in the two topsoil layers, with relative abundance larger than 15\%, respectively. In the soil layer of 0-20 cm (Figure 4a), the relative abundance of Proteobacteria decreased with the order: DFAA2 $>$ DFAA3 $>$ DFAA1 $>$ DFAA4 $>$ CK. The relative abundance of Actinobacteria decreased with the order: CK $>$ DFAA4 $>$ DFAA1 $>$ DFAA3 $>$ DFAA2. The relative abundance of Acidobacteria decreased with the order: DFAA3 $>$ DFAA1 $>$ CK $>$ DFAA $4>$ DFAA2. In the soil layer 
of $20-40 \mathrm{~cm}$ (Figure $4 \mathrm{~b}$ ), the relative abundance of Proteobacteria decreased as: DFAA2 > DFAA1 > DFAA3 $>$ DFAA4 $>$ CK. The relative abundance of Actinobacteria decreased with the following order: CK $>$ DFAA4 $>$ DFAA1 $>$ DFAA3 $>$ DFAA2. The relative abundance of Acidobacteria decreased in the order: DFAA4 $>$ CK $>$ DFAA3 $>$ DFAA2 $>$ DFAA1. The relative abundance of Proteobacteria and Acidobacteria showed different orders in different topsoil layers. Generally, the relative abundance of Proteobacteria was higher in the DFAA treatments than in the CK treatment, with differences of $5 \%$ to $10 \%$. The relative abundance of Actinobacteria was greater in the CK treatment than in the DFAA treatments, with differences of $5 \%$ to $10 \%$. there was no consistent law of the relative abundance of Acidobacteria among the CK treatment and the DFAA treatments in the two topsoil layers. Combined with roots density, we found that the Actinobacteria and Proteobacteria had a positive correlation with the roots amount in the topsoil of $0-20 \mathrm{~cm}$ and $20-40 \mathrm{~cm}$, respectively.

(a)

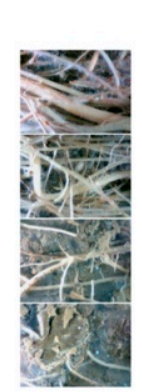

(c)

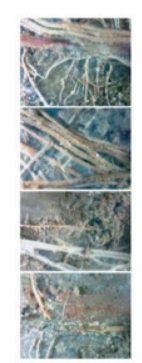

(e)

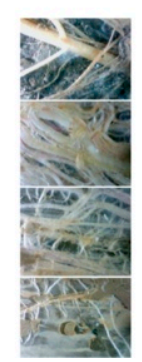

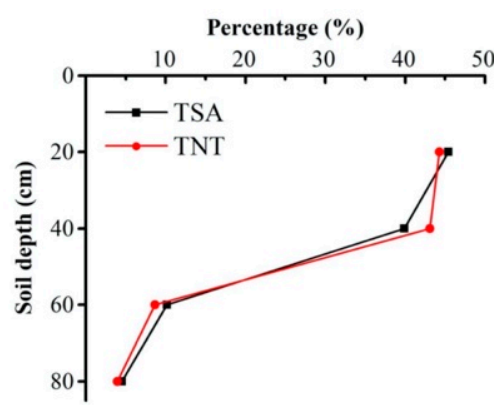

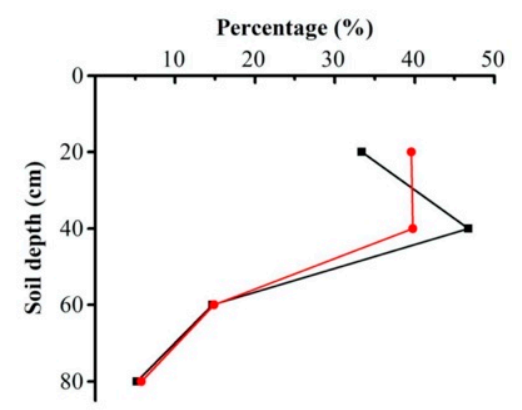

Percentage (\%)

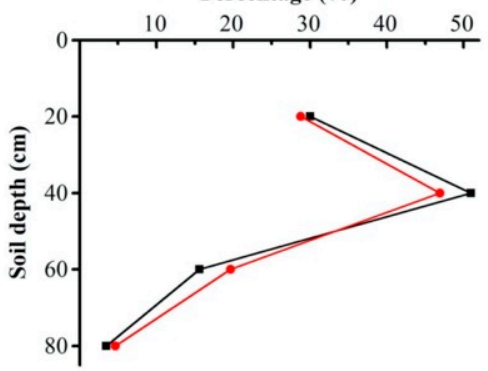

(b)
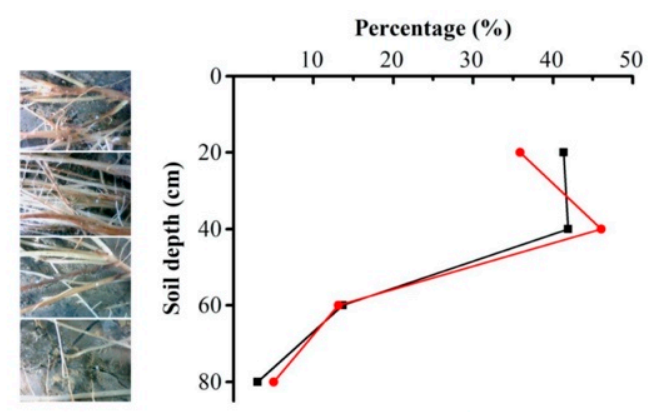

(d)

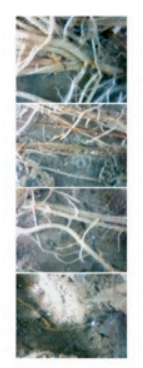

Figure 3. The summer maize roots at mature stage. (a) DFAA1 treatment; (b) DFAA2 treatment; (c) DFAA3 treatment; (d) DFAA4 treatment; (e) CK treatment. The photos in the left of each figure are the roots growing in the corresponding depths. TSA represents the total root surface area; TNT represents the total number of root tips.

\subsection{Leaf Area Index}

In general, the LAI increased first and then decreased in all treatments, and the LAI varied within the range of 0 to 4 (Figure 5). The maximum LAI appeared on 16 August 2018 for all DFAA treatments, with values of $3.65,3.37,3.12$, and 3.33 in DFAA1, DFAA2, DFAA3, and DFAA4 treatment, respectively. While the maximum LAI appeared on 1 September 2018 in the CK treatment, with a value of 3.72. The maximum LAI mainly decreased with the following order: 
CK $>$ DFAA1 $>$ DFAA2 $>$ DFAA4 $>$ DFAA3. At the end of the mature stage, the LAI was about 2 in all treatments.
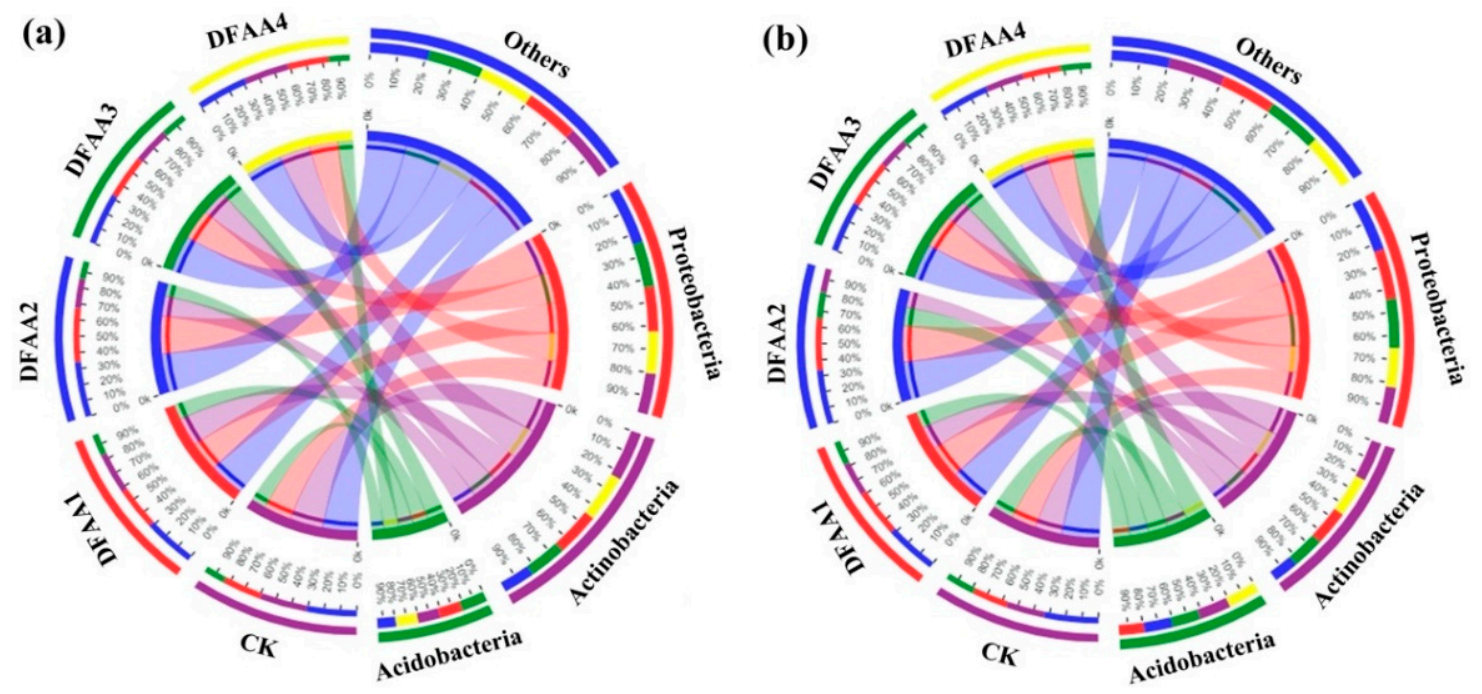

Figure 4. Circos diagram of different treatment samples and soil bacteria at phylum level after DFAA. (a) Soil layer of $0-20 \mathrm{~cm}$; (b) soil layer of $20-40 \mathrm{~cm}$. The small semicircle (left half circle) indicates the bacteria composition in the sample. The color of the outer ribbon represents the different treatments, from which the color of the inner layer is the species, and the length represents the relative abundance of the species in the corresponding treatment. The large semicircle (right half circle) indicates the proportion of species in different treatments at the phylum level. The outer ribbon represents the species, the inner ribbon color represents different treatments, and the length represents the proportion of the treatment in a certain species.

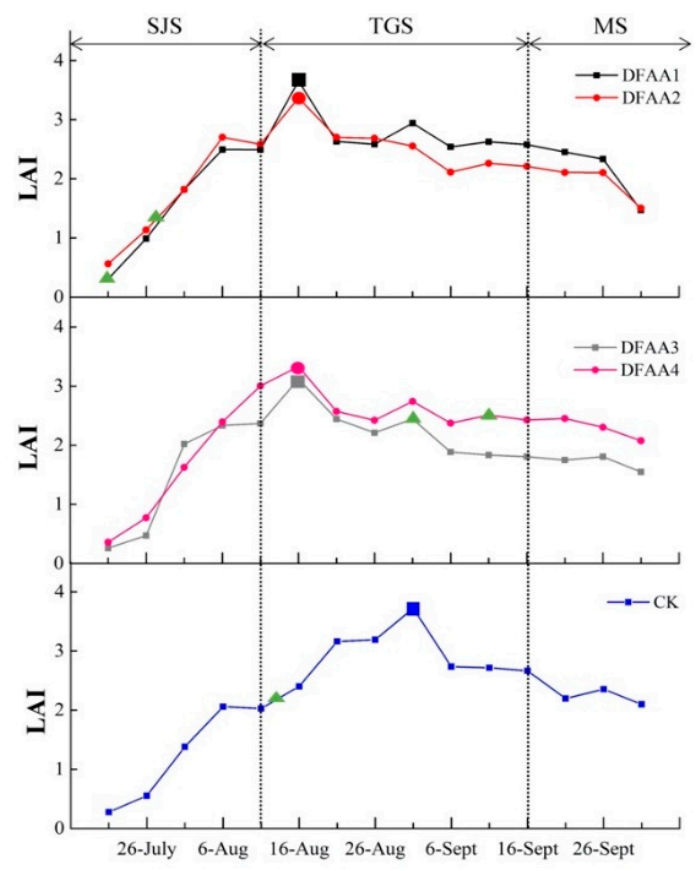

Figure 5. The leaf area index of summer maize in different growth periods. The green triangles are the time point of rainfall in different treatments. The thicker points correspond to the maximum leaf area index. LAI represents the leaf area index. SJS represents the seeding-jointing stage, TGS represents the tasseling-grain filling stage, MS represents the mature stage. 


\subsection{Yield}

For the yield per unit area, the yield was about 5000 to $7000 \mathrm{~kg} \mathrm{ha}^{-1}$, and it was basically 1500 to $2000 \mathrm{~kg} \mathrm{ha}^{-1}$ (25\% to $33 \%$ in proportion) higher in the CK treatment than in the DFAA treatments (Figure 6a). During SJS, in the moderate DFAA treatment, the yield was a little bit higher than that in the light DFAA treatment (about 3\%). However, during TGS, in the moderate DFAA treatment, the yield was apparently lower (about 30\%) than that in the light DFAA treatment. The ear length of summer maize was between 15 to $20 \mathrm{~cm}$ in different treatments. The ear length of summer maize was $5 \mathrm{~cm}$ longer (about 33\% in proportion) in the CK treatment than in the DFAA treatments (Figure 6b). In addition, the ear length was slightly larger in the moderate DFAA treatments (DFAA2 and DFAA4) than in the light DFAA treatments (DFAA1 and DFAA3). As for the total number of grains in one cob, the value was much larger in the CK treatment than in the DFAA treatments, with a difference of about 150 (30\% in proportion) (Figure 6c). During SJS, in the light DFAA treatment, the grain number was $5 \%$ slightly higher than that in the moderate DFAA treatment, while the opposite trend was found during TGS. For the number of ear rows, the value was close in all treatments with approximately 15 (Figure 6d). In the SJS, the number of ear rows was larger in the light DFAA treatment than in the moderate treatment, while an opposite tread appeared in the TGS. The number of ear columns was about 25 in the DFAA treatments. The number of ear columns was about $40 \%$ higher in the CK treatment than in the DFAA treatments (Figure 6e). Also, the value was a little bit larger in the moderate DFAA treatment than in the light DFAA treatment.
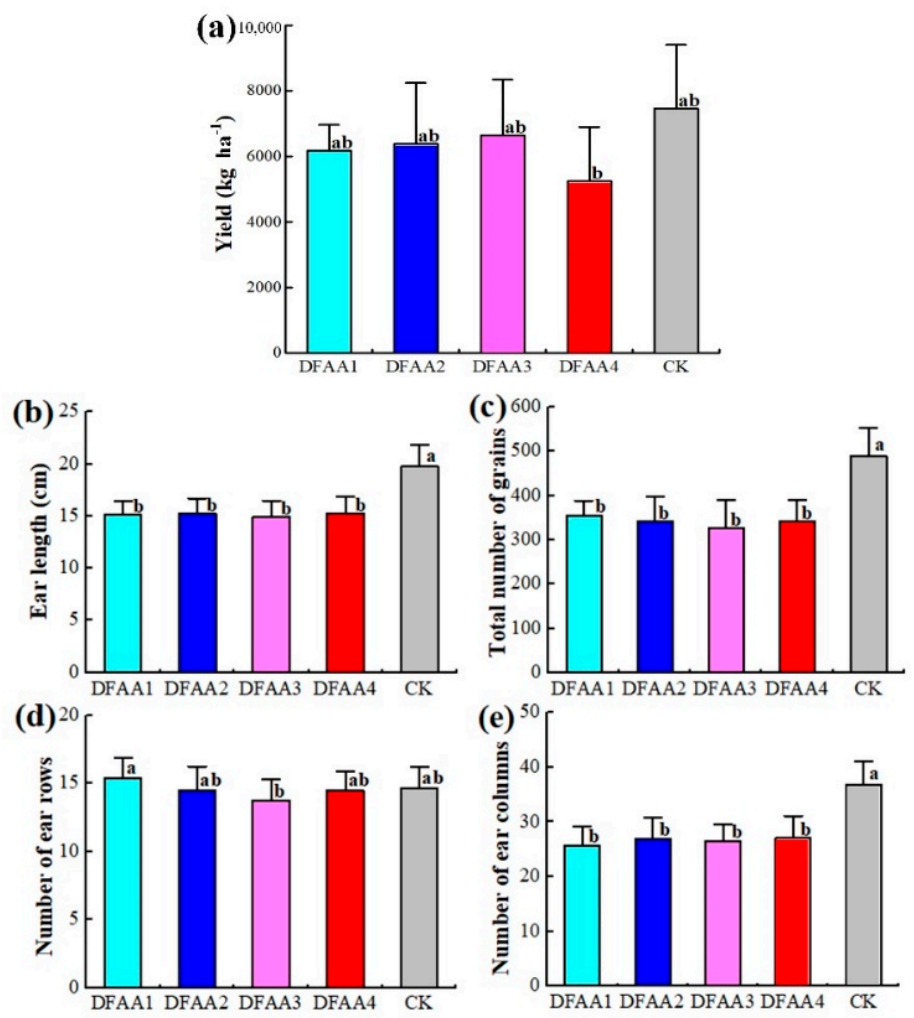

Figure 6. The parameters of summer maize grain yield at harvest. (a) yield; (b) ear length; (c) total number of grains; (d) number of ear rows; (e) number of ear columns. Error bars represent standard deviations $(n=6)$, different letters indicate significant difference among the treatments at 0.05 .

\subsection{Grain Quality}

The crude protein was between $6 \%$ and $8 \%$ in different treatments. The crude protein was about $7 \%$ higher in the moderate DFAA treatments than in the light DFAA treatments (Figure 7a). The value 
in the CK treatment was slightly lower than in the DFAA treatments. The crude starch content was basically about 70\% in all treatments (Figure 7b). In the SJS, the crude starch content was slightly lower in the moderate DFAA treatment than in the light DFAA treatment, and an opposite trend was found in the TGS. The crude fat was among the range of $7 \%$ to $9 \%$ in different treatments. The crude fat content was generally higher in the CK treatment than in the DFAA treatments in the SJS, while the content was greater in the DFAA treatments in the TGS (Figure 7c). In the SJS, the crude fat was 7\% higher in the moderate DFAA treatment than in the light DFAA treatment, and an opposite trend was found in the TGS.
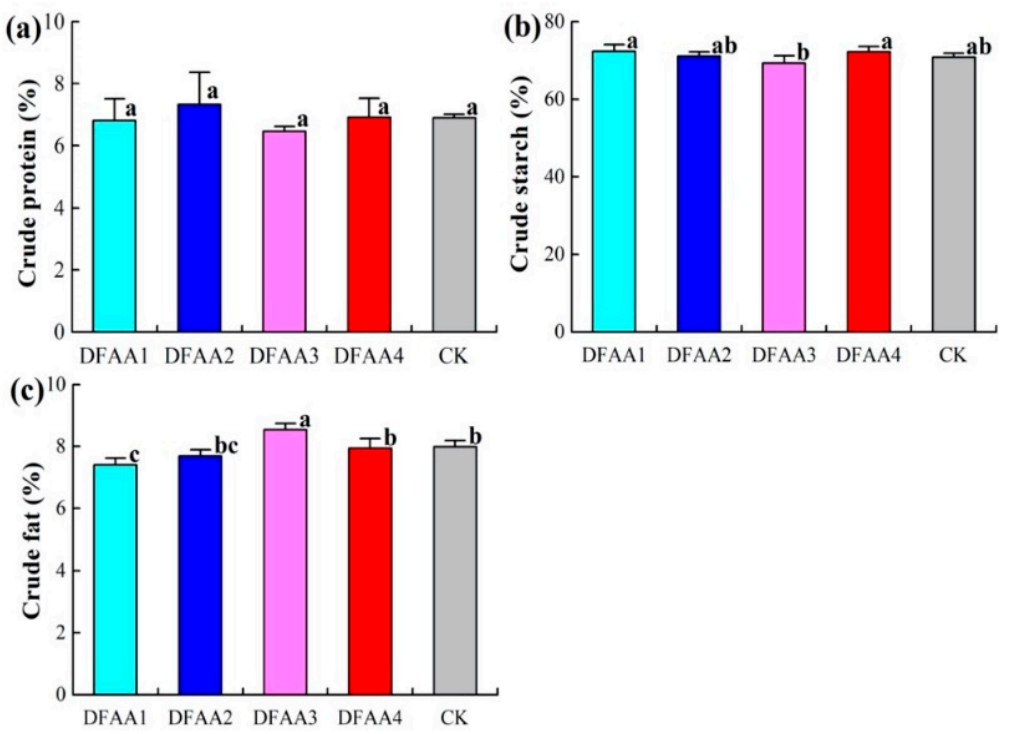

Figure 7. The parameters of summer maize grain quality at harvest. (a) crude protein; (b) crude starch; (c) crude fat. Error bars represent standard deviations $(n=6)$, different letters indicate significant difference among the treatments at 0.05 .

\subsection{Correlation Analysis}

This study was concerned with the DFAA impacts on the growth and yield of summer maize, especially on the key role of roots. The correlation between each two elements after DFAA was analyzed (Figure 8). The results suggest that the yield and grain quality of summer maize were closely correlated to the root system. The yield had a highly positive correlation with the total length of root (TL) and the total number of root tips (TNT), with correlation coefficients of 0.61 and 0.69 , respectively. The crude protein content was slightly positively correlated to all the root parameters, with a coefficient of about 0.2. The crude starch had a highly positive correlation, with the total surface area of root (TSA) and the average diameter of root tips (ADT), of 0.67. There was a positive correlation among the LAI and the parameters of grain yield and quality. The crude fat was slightly positively correlated to the LAI, with a coefficient of 0.2 . The LAI had a slightly positive correlation with the TL and TNT, while a negative correlation was shown with the TSA and the ADT. 


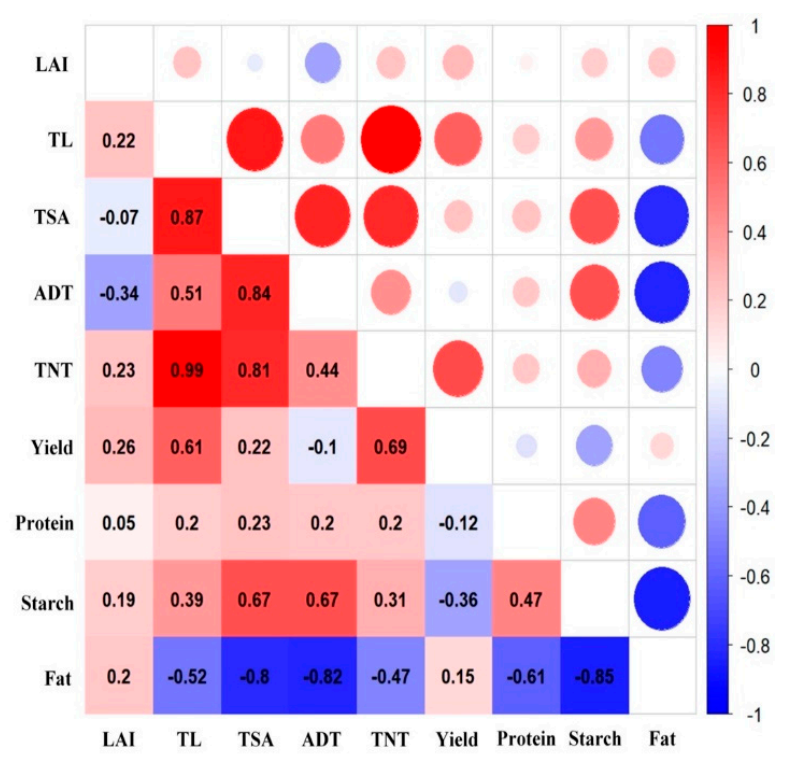

Figure 8. The heat map of correlation between each pair of indices (i.e., root, grain yield, and quality) after drought-flood abrupt alternation in summer maize farmland systems. The blue discs represent the negative correlation between the pair of indices, with the value of -1 . The red discs represent the positive correlation between the pair of indices, with the value of 1 . Note: LAI represents the leaf area index; TL represents the total length of root; TSA represents the total surface area of root; ADT represents the average diameter of root tips; TNT represents the total number of root tips; yield represents the grain yield; protein represents the grain crude protein; starch represents the grain starch; fat represents the grain crude fat.

\section{Discussion}

\subsection{DFAA Effects on the Growth of Summer Maize}

The soil moisture content augmented rapidly in one day in all treatments, which can be explained by the sudden heavy rainfall after long-term drought. The soil porosity increased during long-term drought, the higher porosity absorbed more water in wet conditions, which further augmented the soil moisture content [32]. Then the soil moisture content decreased slowly in the light DFAA treatments, while it continued to increase in the moderate DFAA treatments. It can be inferred that the soil moisture subsiding was more rapid in the light DFAA treatments than in the moderate treatments. Given that the root density was larger in the light DFAA treatments than in the moderate treatments, the water absorbing capacity of root was corresponding greater, which advanced the soil moisture subsiding $[14,16]$. As the roots mainly grew in the SJS, the large water demand led to the relatively lower soil moisture content compared to the TGS $[33,34]$. It can be inferred that the DFAA can intensify the fluctuation of soil moisture content in the topsoil as the range increased with the longer drought duration.

Most roots of summer maize grew in the topsoil of $0-40 \mathrm{~cm}$. The DFAA mainly influenced the roots in the topsoil as well. Previous studies show that soil drying commences under drought [35], and soil moisture content is essential for root growth [36], thus the TSA and TNT in the topsoil changed apparently after DFAA. In the SJS, the longer drought increased the TSA and TNT in the soil layer of $40 \mathrm{~cm}$; this reveals that the drought could advance the roots growing deeply to absorb more water during the root growing period. Previous studies showed that maize is moderately water-stress sensitive while very sensitive during the tasseling, silking, and pollination periods [37,38]. While in the TGS, the root systems were already formed and a longer drought would increase the root death [39].

The main bacterial communities in the summer maize topsoil were phyla Proteobacteria, Actinobacteria and Acidobacteria, which was consistent with other studies [40]. The relative abundance 
of Proteobacteria augmented after longer drought in the SJS, while an opposite trend was found in the TGS. The variation of TSA in the $40 \mathrm{~cm}$ depth was consistent with the Proteobacteria abundance. The relative abundance of Actinobacteria reduced after a longer drought in the SJS, an inverse law appeared in the TGS. The variation of TSA in $20 \mathrm{~cm}$ depth was associated with Actinobacteria abundance. It demonstrates that the number of bacteria was associated with root surface [41]. The relative abundance of Acidobacteria decreased with longer drought duration in DFAA in $0-20 \mathrm{~cm}$, while it increased in $20-40 \mathrm{~cm}$. A similar variation trend was found with the TSA and TNT. Given that Acidobacteria are relatively more abundant in the rhizospheres of healthy plants [42], our results were convenient.

Normally, the LAI of maize presents the trend of increasing first then decreasing throughout the growing season. The LAI is small in the seeding period, augments rapidly during the jointing stage, achieves the maximum in the grain filling stage, then begins to decline $[19,20]$. In our experiment, the maximum LAI appeared in the grain filling stage in the CK treatment, while it appeared after the jointing stage in the DFAA treatments. Compared to the CK treatment, the maximum LAI appeared in advance in the DFAA treatments. The value of maximum LAI in the DFAA treatments was lower than that in the CK treatment. Notably, the LAI was higher for DFAA4 treatment (moderate drought) than for DFAA3 (light drought) during tasseling-grain filling stage. The possible reason is that DFAA4 treatment was located in the southeast while DFAA3 was located in the southwest, thus the DFAA4 treatment was more likely influenced by sunlight than the DFAA3 treatment. The DFAA1 and DFAA2 treatment were located in the northeast and northwest, respectively. It can be inferred that the DFAA had negative impacts on leaf growth but was not the only determining factor. As long-term drought hinders maize growth $[43,44]$, the leaf growing period shortened during DFAA, then the maximum LAI was achieved in advance with a lower value than in the normal condition.

The yield would reduce when DFAA occurred, with lower ear length and total number of grains. The total number of columns reduced as the ear diameter decreased after DFAA. Both the long-term drought and flood have negative impacts on the maize yield [24,45]. As the DFAA has the above two periods, it demonstrates the yield reduction effects of extreme climate change. In the SJS, the yield was larger with the longer drought duration in the DFAA events, which can be explained as: (i) the drought has less impacts on the seeding period compared to other periods, which promotes root growth during the long-term drought, and in turn the deep roots can resist the drought [46]; and (ii) the root surface was larger in the moderate DFAA, which promotes nutrient absorption [47]. Previous studies showed that yield would slightly increase when the drought occurred in the seeding period [48]. Li et al. found that the irrigation after moderate drought could increase the yield in the jointing stage as the water-use efficiency augmented [49]. Our results coincide with previous studies. While in the TGS, the yield reduced largely with longer drought. Given that the TGS is the key period for fruit formation, the drought would have significant influences on the yield [50,51]. The maize yield may decrease by $30 \%$ when drought occurred in the grain filling stage [23,52]. Our study shows that the yield was $25 \%$ to $33 \%$ higher in the CK treatment than in the DFAA treatments, which coincides with previous studies. The root surface decreased with longer drought duration as well. It can be concluded that the roots play an important role for maize growth, especially in the topsoil of $0-40 \mathrm{~cm}$.

Previous studies show that drought has a negative impact on yield, while may augment the grain crude protein content $[53,54]$. The flood reduced the grain crude protein [55]. Some studies show that the crude starch and crude fat content have no significant correlation with water content and are mainly affected by the light and base temperature [56]. Other studies reveal that the crude fat content would augment when the drought occurs in the grain filling stage, with basically no impacts on the crude starch [25]. In our experiment, the DFAA promoted grain crude protein formation. It can be inferred that the long-term drought effect was evident on the grain crude protein content. The grain crude protein increased more compared to the CK treatment when DFAA took place in the SJS than in the TGS. There was no obvious difference of crude starch content among the DFAA treatments and CK treatment. It demonstrates that the water condition has no significant effects on the grain crude starch, 
thus the crude starch did not change as much as the water condition during the DFAA. The crude fat in the TGS was higher than in the CK treatment, while the content in the SJS was slightly lower than in the CK treatment. The result coincides with other studies that found that the drought in the grain filling stage would augment the grain crude fat content.

\subsection{Mechanism of DFAA Effects on the Growth of Summer Maize}

This study explored the light and moderate DFAA effects on the growth of summer maize, mainly focusing on the roots, leaf area index, yield, and grain quality. Other environmental factors such as soil moisture content and soil bacterial communities were analyzed as well. The results revealed that the DFAA has different impacts on the summer maize growth in different growing periods (Figure 9). It can be learned that the LAI reduced under DFAA, and the maximum LAI would appear in advance. Given that the soil bacterial communities influenced the roots' growth, we observed that Actinobacteria and Proteobacteria had a positive correlation with the amount of roots in the topsoil of $0-20 \mathrm{~cm}$ and $20-40 \mathrm{~cm}$, respectively. Acidobacteria was more abundant with more healthy roots. When DFAA happened in the SJS, the roots reduced in the topsoil of 0-20 cm, while more roots were found in the topsoil of 20-40 cm. An opposite trend was observed when DFAA occurred in the TGS. The amount of roots in a depth of $20-40 \mathrm{~cm}$ had significantly positive impacts on the yield. The yield would decrease under DFAA compared to CK treatment. While the value was slightly greater with longer drought of the DFAA in the SJS, it was much lower in the TGS. DFAA would augment the grain crude protein content. No apparent correlation was found between the crude starch content and the DFAA. Longer drought had obvious negative impacts on grain crude fat in the TGS.

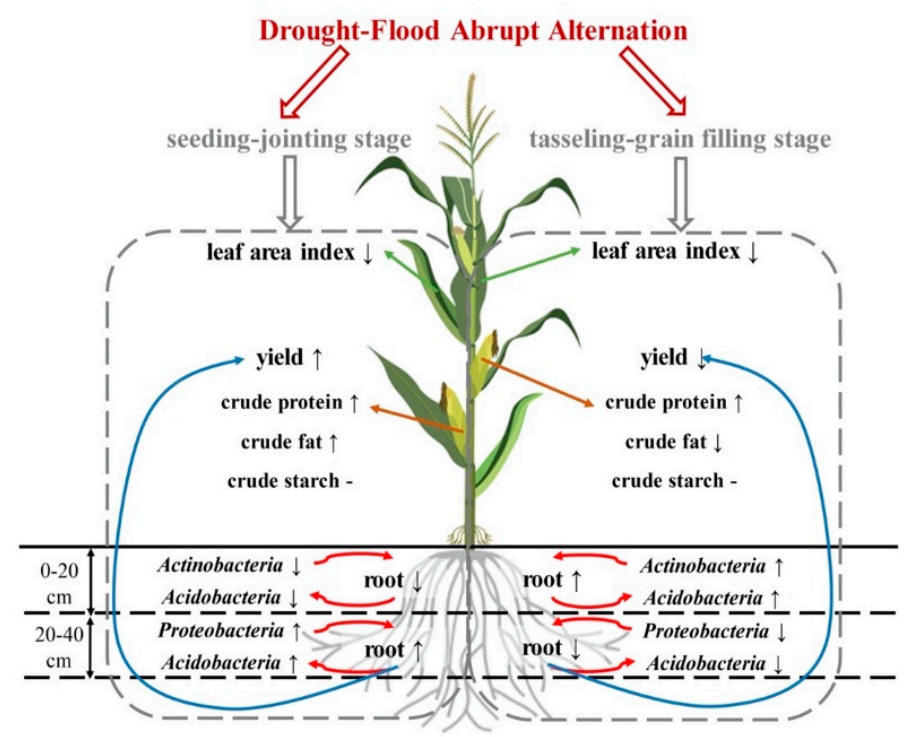

Figure 9. Mechanisms of the effects of DFAA on the growth of summer maize. The DFAA has different impacts on the summer maize growth when DFAA occurs in different growing periods. The leaf area index reduced under DFAA. The soil bacterial communities influenced the roots growth. The Actinobacteria and Proteobacteria had a positive correlation with the roots amount in the topsoil of 0-20 cm and 20-40 cm, respectively. Acidobacteria was more abundant with more healthy roots. When DFAA happened in the seeding-jointing stage, the roots reduced in the topsoil of $0-20 \mathrm{~cm}$, while more roots were found in the topsoil of 20-40 cm. An opposite trend was observed when DFAA occurred in the tasseling-grain filling stage. The roots amount in the $20-40 \mathrm{~cm}$ had significantly positive impacts on the yield. The yield would increase with longer drought of the DFAA in the seeding-jointing stage, while it reduced in the tasseling-grain filling stage. DFAA would augment the grain crude protein content. The crude fat was obviously affected by the longer drought in the tasseling-grain filling stage. The DFAA had no apparent impacts on the crude starch content. 


\section{Conclusions}

This study explored the DFAA impacts on the growth of summer maize in different growing periods. The roots in the depth of $40 \mathrm{~cm}$ play a key role for the yield. The roots surface and root tips in the $40 \mathrm{~cm}$ increased with longer drought in DFAA occurring in the SJS; the yield would augment as well. Opposite trends were found in the TGS. The yield reduced under DFAA compared to the CK treatment. The DFAA reduced the LAI, and promoted the maximum LAI achieving in advance. The grain crude protein negatively correlated to water content, thus longer drought in the DFAA would increase its content. The drought has evidently negative impacts on the grain crude fat in the TGS, while it has no obvious influence in the SJS. The grain crude starch was not very correlated to the water condition.

In general, the DFAA has significant impacts on the yield and grain quality of summer maize, mainly due to the soil moisture content and root growth. The mechanisms are complex and need further study. This study mainly focused on the root growth condition at the mature stage. Further studies can be applied on the consecutive root observations during the summer maize growing season. Meanwhile, it is necessary to carry out field experiments on the DFAA with different flood levels and other drought-flood combinations. This study could provide references for extreme climate events and adaptation-strategy studies, as well as serve as a guide for agricultural management.

Author Contributions: Conceptualization, W.B., B.W., and D.Y.; methodology, W.B., B.W., and D.Y; software, W.B. and M.W.; validation, W.B., M.W., and J.W.; formal analysis, W.B. and M.W.; investigation, W.B. and M.W.; resources, B.W. and D.Y.; data curation, W.B. and M.W.; writing-Original draft, W.B. and M.W.; writing-Review and editing, W.B.; visualization, W.B., M.W., and Y.Y.; supervision, B.W. and D.Y.; project administration, B.W. and D.Y.; funding acquisition, B.W. and D.Y. All authors have read and agreed to the published version of the manuscript.

Funding: This work was supported by the Chinese National Natural Science Foundation (No. 51725905 and No. 91547209), the National Key Research and Development Project (No. 2016YFA0601503), and the Research Fund of the State Key Laboratory of Simulation and Regulation of Water Cycle in River Basin (No. SKL2018TS02).

Acknowledgments: Many thanks to Wudaogou Experimentation Research Station for their full support and help during this study. We also thank the editors and anonymous reviewers.

Conflicts of Interest: The authors declare no conflicts of interest.

\section{Abbreviations}

The following abbreviations are used in this manuscript.

CK control system

DFAA drought-flood abrupt alternation

DFAA1 light drought-light flood treatment in the seeding-jointing stage

DFAA2 moderate drought-light flood treatment in the seeding-jointing stage

DFAA3 light drought-light flood treatment in the tasseling-grain filling stage

DFAA4 moderate drought-light flood treatment in the tasseling-grain filling stage

LAI leaf area index

SIS seeding-jointing stage (i.e., seeding stage and jointing stage)

TGS tasseling-grain filling stage (i.e., tasseling stage and grain filling stage)

\section{References}

1. Elleder, L. Reconstruction of the 1784 flood hydrograph for the Vltava River in Prague, Czech Republic. Glob. Planet. Chang. 2010, 70, 117-124. [CrossRef]

2. Meng, J.; Yao, P.; Bianchi, T.S.; Li, D.; Zhao, B.; Xu, B.; Yu, Z. Detrital phosphorus as a proxy of flooding events in the Changiiang River Basin. Sci. Total Environ. 2015, 517, 22-30. [CrossRef] [PubMed]

3. Wilby, R.L.; Keenan, R. Adapting to flood risk under climate change. Prog. Phys. Geogr. 2012, 36, 348-378. [CrossRef] 
4. Frich, P.; Alexander, L.V.; Della-Marta, P.; Gleason, B.; Haylock, M.; Klein Tank, A.M.G.; Peterson, T. Observed coherent changes in climatic extremes during the second half of the twentieth century. Clim. Res. 2002, 19, 193-212. [CrossRef]

5. Zhai, P.; Zhang, X.; Wan, H.; Pan, X. Trends in total precipitation and frequency of daily precipitation extremes over China. J. Clim. 2005, 18, 1096-1108. [CrossRef]

6. Wu, Z.; He, J.; Li, J. The Summer Drought-Flood Coexistence in the Middle and Lower Reaches of the Yangtze River and Analysis of its Air-Sea Background Feathers in Anomalous Years. J. Atmos. Sci. 2006, 30, 570-577.

7. Egamberdiyeva, D. The effect of plant growth promoting bacteria on growth and nutrient uptake of maize in two different soils. Appl. Soil Ecol. 2007, 36, 184-189. [CrossRef]

8. Sposito, G. Green Water and Global Food Security. Vadose Zone J. 2013, 12, 4. [CrossRef]

9. Mohammadkhani, N.; Heidari, R. Effects of water stress on respiration, photosynthetic pigments and water content in two maize cultivars. Pak. J. Biol. Sci. 2007, 10, 4022-4028.

10. Zhou, X.; Zhang, Y.; Ji, X.; Downing, A.; Serpe, M. Combined effects of nitrogen deposition and water stress on growth and physiological responses of two annual desert plants in northwestern China. Environ. Exp. Bot. 2011, 74, 1-8. [CrossRef]

11. Zinselmeier, C.; Westgate, M.E.; Schussler, J.R.; Jones, R.J. Low Water Potential Disrupts Carbohydrate Metabolism in Maize (Zea mays L.) Ovaries. Plant Physiol. 2016, 107, 385-391. [CrossRef] [PubMed]

12. Campos, H.; Cooper, M.; Habben, J.E.; Edmeades, G.O.; Schussler, J.R. Improving drought tolerance in maize: A view from industry. Field Crop. Res. 2004, 90, 19-34. [CrossRef]

13. Suraj, B. Effect of water logging on maize. Indian J. Agric. Res. 1977, 11, 147-151.

14. Ahmed, M.A.; Zarebanadkouki, M.; Kaestner, A.; Carminati, A. Measurements of water uptake of maize roots: The key function of lateral roots. Plant Soil 2016, 398, 59-77. [CrossRef]

15. Lynch, J.P.; Chimungu, J.G.; Brown, K.M. Root anatomical phenes associated with water acquisition from drying soil: Targets for crop improvement. J. Exp. Bot. 2014, 65, 6155-6166. [CrossRef] [PubMed]

16. Stasovski, E.; Peterson, C.A. The effects of drought and subsequent rehydration on the structure and vitality of Zea mays seedling roots. Can. J. Bot. 2007, 69, 1170-1178. [CrossRef]

17. Çakir, R. Effect of water stress at different development stages on vegetative and reproductive growth of corn. Field Crop. Res. 2004, 89, 1-16. [CrossRef]

18. Katerji, N.; Van Hoorn, J.W.; Hamdy, A.; Mastrorilli, M. Comparison of corn yield response to plant water stress caused by salinity and by drought. Agric. Water Manag. 2004, 65, 95-101. [CrossRef]

19. Gitelson, A.A.; Viña, A.; Arkebauer, T.J.; Rundquist, D.C.; Keydan, G.; Leavitt, B. Remote estimation of leaf area index and green leaf biomass in maize canopies. Geophys. Res. Lett. 2003, 30. [CrossRef]

20. Dwyer, L.M.; Stewart, D.W. Indicators of Water Stress in Corn (Zea mays L.). Can. J. Plant Sci. 1984, 64, 537-546. [CrossRef]

21. Shumway, C.R.; Cothren, J.T.; Serna-Saldivar, S.O.; Rooney, L.W. Planting Date and Moisture Effects on Yield, Quality, and Alkaline-Processing Characteristics of Food-Grade Maize. Crop Sci. 1992, 32, 1265. [CrossRef]

22. Ma, X.; Cui, Z.; Chen, J.; Xiao, C.L.; Zhang, L.J.; Wang, Q.X. Effect of Drought Stress during Seedling Stage on the Content of Grain Crude Protein, and Lysine of Maize. J. Maize Sci. 2006, 14, 71-74.

23. Wang, P.W.; Dai, J.Y.; Wei, Y.P. The effects of drought stress on yield and quality of maize. J. Maize Sci. 1999, 7, 102-106.

24. Steudle, E. Water uptake by plant roots: An integration of views. Plant Soil 2000, 226, 45-56. [CrossRef]

25. Singh, S.; Singh, G.; Singh, P.; Singh, N. Effect of water stress at different stages of grain development on the characteristics of starch and protein of different wheat varieties. Food Chem. 2008, 108, 130-139. [CrossRef]

26. Wang, X.L.; Qin, R.R.; Sun, R.H.; Hou, X.G.; Qi, L.; Shi, J. Effects of plant population density and root-induced cytokinin on the corn compensatory growth during post-drought rewatering. PLoS ONE 2018, 13, e0198878. [CrossRef]

27. Huang, R. Research on Evolution and Countermeasures of Droughts-Floods Abrupt Alternation Events in Huaihe River Basin. Ph.D. Thesis, China Institute of Water Resources and Hydropower Research, Beijing, China, 2015.

28. Bi, W.; Weng, B.; Yuan, Z.; Yang, Y.; Xu, T.; Yan, D.; Ma, J. Evolution of Drought-Flood Abrupt Alternation and Its Impacts on Surface Water Quality from 2020 to 2050 in the Luanhe River Basin. Int. J. Environ. Res. Public Health 2019, 16, 691. [CrossRef] 
29. Liu, S.H. Research on Drought Risk Mitigation Based on Water Resources System: Taking Daqing River Basin for an Example. Master's Thesis, China Institute of Water Resources and Hydropower Research, Beijing, China, 2014.

30. Lu, R.K. Analysis Methods of Soil Agricultural Chemistry, 1st ed.; China Agricultural Science and Technology Press: Beijing, China, 1999.

31. Krzywinski, M.; Schein, J.; Birol, I.; Connors, J.; Gascoyne, R.; Horsman, D.; Jones, S.J.; Marra, M.A. Circos: An information aesthetic for comparative genomics. Genome Res. 2009, 19, 1639-1645. [CrossRef]

32. Zhang, Q.; Shao, M.; Jia, X.; Wei, X. Changes in soil physical and chemical properties after short drought stress in semi-humid forests. Geoderma 2019, 338, 170-177. [CrossRef]

33. Siatyer, R.O. Plant-Water Relationships; Academic Press: New York, NY, USA, 1976.

34. Romdhane, L.; Awad, Y.M.; Radhouane, L.; Dal Cortivo, C.; Barion, G.; Panozzo, A.; Vamerali, T. Wood biochar produces different rates of root growth and transpiration in two maize hybrids (Zea mays L.) under drought stress. Arch. Agron. Soil Sci. 2019, 65, 846-866. [CrossRef]

35. Suriyagoda, L.D.B.; Ryan, M.H.; Renton, M.; Lambers, H. Plant Responses to Limited Moisture and Phosphorus Availability: A Meta-Analysis. In Advances in Agronomy, 1st ed.; Elsevier Inc.: Amsterdam, The Netherlands, 2014.

36. Li, Y.; Yao, N.; Tang, D.; Chau, H.W.; Feng, H. Soil water repellency decreases summer maize growth. Agric. For. Meteorol. 2019, 266, 1-11. [CrossRef]

37. Eszter, N.; Lajos, H. Physiological Responses of Selected Vegetable Crop Species to Water Stress. Agronomy 2019, 9, 447 .

38. Nemesk'eri, E.; Molnár, K.; Rácz, C.; Dobos, A.C.; Helyes, L. Effect of Water Supply on Spectral Traits and Their Relationship with the Productivity of Sweet Corns. Agronomy 2019, 9, 63. [CrossRef]

39. Suriyagoda, L.D.B.; Ryan, M.H.; Renton, M.; Lambers, H. Above- and below-ground interactions of grass and pasture legume species when grown together under drought and low phosphorus availability. Plant Soil 2011, 348, 281-297. [CrossRef]

40. Li, X.; Rui, J.; Xiong, J.; Li, J.; He, Z.; Zhou, J.; Yannarell, A.C.; Mackie, R.I. Functional potential of soil microbial communities in the maize rhizosphere. PLOS ONE 2014, 9, e112609. [CrossRef]

41. Cavaglieri, L.; Orlando, J.; Etcheverry, M. Rhizosphere microbial community structure at different maize plant growth stages and root locations. Microbiol. Res. 2009, 164, 391-399. [CrossRef]

42. Wen, X.Y.; Dubinsky, E.; Yao, W.; Rong, Y.; Fu, C. Wheat, maize and sunflower cropping systems selectively influence bacteria community structure and diversity in their and succeeding crop's rhizosphere. J. Integr. Agric. 2016, 15, 1892-1902. [CrossRef]

43. Sinclair, T.R.; Bennett, J.M.; Muchow, R.C. Relative Sensitivity of Grain Yield and Biomass Accumulation to Drought in Field-Grown Maize. Crop Sci. 1990, 30, 690. [CrossRef]

44. Rohman, M.M.; Islam, M.R.; Naznin, T.; Omy, S.H.; Hasanuzzaman, M. Maize Production under Salinity and Drought Conditions: Oxidative Stress Regulation by Antioxidant Defense and Glyoxalase Systems. In Plant Abiotic Stress Tolerance; Springer: Berlin/Heidelberg, Germany, 2019.

45. NeSmith, D.S.; Ritchie, J.T. Effects of soil water-deficits during tassel emergence on development and yield component of maize (Zea mays). Field Crop. Res. 1992, 28, 251-256. [CrossRef]

46. Zhang, Y.J. Effect of Earlier-Stage Drought on Yield and Quality of Maize. Master's Thesis, Northwest A \& F University, Yanglin, China, 2007.

47. Chaudhary, S.; Shankar, A.; Singh, A.; Prasad, V. Usefulness of Penicillium in Enhancing Plants Resistance to Abiotic Stresses. In New and Future Developments in Microbial Biotechnology and Bioengineering; Elsevier B.V.: Rio de Janeiro, Brazil, 2017.

48. Shao, G.Q. Study on the Coupling Effects of Controlled Release Urea and Water on Nitrogen and Water Utilization, Yield and Quality of Maize. Master's Thesis, Shandong Agricultural University, Taian, China, 2008.

49. Li, F.; Wei, C.; Zhang, F.; Zhang, J.; Nong, M.; Kang, S. Water-use efficiency and physiological responses of maize under partial root-zone irrigation. Agric. Water Manag. 2010, 97, 1156-1164. [CrossRef]

50. Li, S.M.; Dong, X.W.; Chen, J.H. Effect of different target water content in soil on photosynthetic property and yield of summer-sowing corn. Acta Agric. Boreali Sin. 1994, 14, 55-59.

51. Li, L.J.; Gu, W.R.; Meng, Y.; Wang, Y.L.; Wei, S. Physiological and biochemical mechanism of spermidine improving drought resistance in maize seedlings under drought stress. J. Appl. Ecol. 2018, 29, 554-564. 
52. Wang, P.H. Effect of Meteorological Conditions on Maize Yield and Quality. Master's Thesis, Shenyang Agricultural University, Shenyang, China, 2017.

53. Kniep, K.R.; Mason, S.C. Lysine and Protein Content of Normal and Opaque-2 Maize Grain as Influenced by Irrigation and Nitrogen. Crop Sci. 1991, 31, 177. [CrossRef]

54. Oktem, A. Effect of water shortage on yield, and protein and mineral compositions of drip-irrigated sweet corn in sustainable agricultural systems. Agric. Water Manag. 2008, 95, 1003-1010. [CrossRef]

55. Cai, X.M. Effects of Water Stress on Grain Yield and Starch Physicochemical Properties of Waxy Maize. Master's Thesis, Yangzhou University, Yangzhou, China, 2016.

56. Ren, B.Z. Effects of Waterlogging on Grain Yield, Quality and Physiological Characteristics of Summer Maize. Master's Thesis, Shandong Agricultural University, Taian, China, 2014.

C 2019 by the authors. Licensee MDPI, Basel, Switzerland. This article is an open access article distributed under the terms and conditions of the Creative Commons Attribution (CC BY) license (http://creativecommons.org/licenses/by/4.0/). 